Introduction/Background* Sentinel node presents almost the standard of care regarding low and intermediate-risk endometrial cancer patients. However, every oncological team should continuously evaluate outcomes of this relatively newly implied technique. Main objective of the present study is to present the surgical outcomes of laparoscopic sentinel node technique in low and intermediate-risk endometrial cancer patients.

Methodology A prospective cohort study was initiated on 03/ 2020 enrolling patients with low and intermediate-risk endometrial cancer being eligible for total laparoscopic hysterectomy and laparoscopic pelvic sentinel node. Primary outcomes of the study was the rate of successfully detected sentinel nodes, number of resected nodes as well as nodal status of resected notes. Pilot results of this cohort are presented in the current study.

Result(s)* There were overall 11 cases performed during 03/ $2020-05 / 2021$, of which 8 were low and 3 were intermediaterisk endometrial cancer patients. Successful bilateral detection of SLN was achieved in 8 cases (72.7\%), unilateral detection in 2 cases $(18,2 \%)$ while no detection in 1 case. Median number of resected nodes was 2.5 nodes from the left side and 3 nodes from the right side. No lymph node was observed to be invaded in this sample of enrolled patients. Postoperative period was uneventful in all patients.

Conclusion* SLN is the standard of treatment in low and intermediate-risk endometrial cancer patients. Continuous training improves surgical technique thereafter optimizing surgical and oncological outcome.

\section{ENDOMETRIAL CLEAR CELL CARCINOMA (ECCC): A A DECADE OF EXPERIENCE FROM A LARGE CANCER CENTRE}

${ }^{1} S$ Addley ${ }^{*},{ }^{2} \mathrm{M}$ Abdalla, ${ }^{2} \mathrm{SL}$ Smyth, ${ }^{2} \mathrm{~N}$ Sadeghi, ${ }^{2} \mathrm{~A}$ Sattar, ${ }^{2} \mathrm{~S}$ Spencer, ${ }^{2} \mathrm{~K}$ Gkorila, ${ }^{2} \mathrm{~K}$ Zarrindej, ${ }^{2} \mathrm{~V}$ Thanh, ${ }^{2} \mathrm{~J}$ Rencher, ${ }^{2} \mathrm{G}$ Sharma, ${ }^{2} \mathrm{~A}$ Khasif, ${ }^{2} \mathrm{M}$ Alazzam, ${ }^{2} \mathrm{H}$ Soleymani Majd. ${ }^{1}$ University Hospitals of Derby and Burton NHS Foundation Trust, Gynaecology Oncology; ${ }^{2}$ Oxford University Hospitals NHS Foundation Trust, Gynaecology Oncology

\subsection{6/ijgc-2021-ESGO.166}

Introduction/Background* ECCCs are non-endometrioid (type II) cancers. Representing 3\% of uterine malignancies, ECCCs are not hormonally-driven, but aggressive - with high rates of LVSI, metastases and extra-pelvic relapse. Five-year survival is $60 \%$. Latest European guidance (2020) recommends primary surgery - incorporating sentinel or pelvic lymph node dissection (PLND); but omitting omentectomy in stage I disease. Excluding those with tumour confined to endometrium, adjuvant chemo-radiation is recommended.

Methodology All patients treated for ECCC in a large cancer centre between 2009-2019 were identified and data collected retrospectively.

Result(s)* 17 patients were identified, representing $<2 \%$ uterine malignancies treated. Mean age was 68.6years and BMI $26.8 \mathrm{~kg} / \mathrm{m} 2$. $82.4 \% \quad(\mathrm{n}=14)$ presented with post-menopausal bleeding and $11.7 \%(n=2)$ were diabetic.

All patients underwent primary surgery (total hysterectomy and bilateral salpingo-oophrectomy). 94.1\% $(\mathrm{n}=16)$ had PLND and omental biopsy. All were grade $3 ; 70.6 \%(n=12)$ LVSI positive; and endometrial hyperplasia co-existed in 1 case. $76.5 \%$ were stage $1 ; 5.9 \%$ stage II; and $17.6 \%$ stage III. 94.1\% $(n=16)$ received adjuvant treatment: vault brachytherapy in $58.8 \%$; reserving chemotherapy for stage III.
$17.6 \%(n=3)$ recurred: on average 22.3 months from surgery and most often (66.7\%) upper abdominally. All patients with relapse were high grade with LVSI; and 2/3 stage III. 5-year survival was $75 \%$ overall; $66.7 \%$ in advanced disease.

Conclusion* In keeping with literature, our experience suggests ECCC is rare and not associated with obesity, diabetes, endometrial hyperplasia or omental disease. High grade, LVSI and advanced stage appear to be risk factors for upper abdominal recurrence. Whilst our stage III survival data is as expected, relatively favourable overall figures likely reflect the high proportion of early stage disease captured. Latest guidance may encourage more sentinel nodes, less omental surgery, and a switch from vault brachytherapy to wider administration of chemo-radiotherapy for ECCC.

\section{OUTCOMES OF FEMALE GENITAL TRACT CARCINOSARCOMAS - FIFTEEN-YEAR EXPERIENCE FROM A CANCER CENTRE IN INDIA}

${ }^{1} \mathrm{D}$ Bose*, 'S Sambasivan, ${ }^{1} \mathrm{PN}$ Rema, ${ }^{2} \mathrm{FV}$ James, ${ }^{3} \mathrm{P} \mathrm{T} \mathrm{R},{ }^{4} \mathrm{PS}$ George. ${ }^{1}$ Regional Cancer Centre, Thiruvananthapuram, Thiruvananthapuram, India; ${ }^{2}$ Regional Cancer Centre, Thiruvananthapuram, Radiation Oncology, Thiruvananthapuram, India; ${ }^{3}$ Regional Cancer Centre, Thiruvananthapuram, Pathology, Thiruvananthapuram, India; ${ }^{4}$ Regional Cancer Centre, Thiruvananthapuram, epidemiology and biostatistics, Thiruvananthapuram, India

\subsection{6/ijgc-2021-ESG0.167}

Introduction/Background* Owing to scarce and small-sampled studies from India about uterine carcinosarcomas, we embarked on this retrospective study, to assess clinicopathologic factors, treatment and recurrence patterns and to ascertain survival outcomes of these cancers.

Methodology Retrospective analysis of all patients who presented to our tertiary care cancer centre with a diagnosis of carcinosarcoma of female genital tract between January 2004 and December 2018. Clinicopathological features, treatment details, follow-up, recurrence and survival were collected from medical records. Chi-square test and Fisher Exact test were used to compare categorical data. Overall and disease-free survival (OS and DFS) were calculated using the Kaplan-Meier method and significance calculated by $\log$ rank test.

Result(s)* 101 patients presented with diagnosis of female genital tract carcinosarcoma during the study period. Of these 83 $(81.8 \%)$ were uterine, 12 ovarian, 2 cervical, 3 vaginal and one of unknown origin. Median OS for uterine tumours was 44 months whereas for ovarian, cervical and vaginal were 22, 17 and 23 months, respectively $(\mathrm{p}=.080)$. Due to small numbers of extrauterine carcinosarcomas, only uterine lesions were further analysed. Of 62 analysable uterine carcinosarcomas, $61.3 \%$ had early stage disease (stage I) and $38.7 \%$ had advanced disease. 18\% had nodal involvement. On follow up, there were 12 patients with locoregional recurrences and 18 with distant metastases. Histology of carcinosarcoma with homologous elements had more survival, although non-significant than those with heterologous or rhabdomyosarcoma (45 vs 30 or 18 months).

With a median follow up of 63 months, median OS was 44 months and DFS of 23 months. Lymph node involvement and lack of primary surgery had a dismal survival of only 4 months each. Stagewise OS - Stage IA- 101 months, IB-44, II-30, IIIA/B- 34, IIIC- 4, IV-12 months. In stage IIIC disease, 
chemotherapy with radiotherapy conferred better OS than chemo alone (36 months vs 4 months, $\mathrm{p}=0.006$ ).

Conclusion* Non-uterine carcinosarcomas had poorer survival than their uterine counterparts. Our cohort of uterine carcinosarcomas had more patients with early-stage disease.. Nodal involvement carries poor prognosis. On subgroup survival analysis, adjuvant radiation in combination with chemotherapy showed benefit, with significant effect seen in stage III cancers.

\section{CIMICIFUGA RACEMOSA EXTRACT EFFECTS ON ENDOMETRIAL AND OVARIAN CELL LINES}

M Sinreih*, K Gregoric, K Marton, T Lanisnik Rizner. faculty of medicine, university of ljubljana

\subsection{6/ijgc-2021-ESGO.168}

Introduction/Background* In postmenopausal women estrogen levels depend exclusively upon the local formation from steroid precursors dehydroepiandrosterone-sulfate and estrone-sulfate (E1-S). The reduced estrogen levels are associated with menopausal symptoms, which often occur in peri- and postmenopausal patients. To mitigate these symptoms nowadays more women choose medicine of natural origin, e.g. extracts from Cimicifuga racemose (CE) instead of hormone replacement therapy, which is associated with increased risk of breast cancer, stroke and pulmonary embolism. While CE treatment is considered as safe, little is known about its effects on healthy endometrial or ovarian tissue and even less on hormone-dependent malignancies like endometrial and ovarian cancer that arise in this population of women. The aim of our study was to examine the influence of CE on the expression of genes encoding E1-S transporters and estrogen biosynthetic and metabolic enzymes in control and cancerous endometrial and ovarian cell lines.

Methodology Control endometrial cell line (HIEEC), control ovarian cell line (HIO80) and cell lines of well differentiated endometrial carcinoma (Ishikawa and HEC-1-A), moderately differentiated adenosquamous carcinoma (RL-95-2), poorly differentiated endometrial carcinoma (KLE) and high grade ovarian serous adenocarcinoma (Kuramochi, COV62 and OVSAHO) were exposed to $\mathrm{CE}$ in different concentrations for 72h. The expression of 9 E1-S transporter genes (SLCO4C1, SLC51A, ABCC1, ABCC4, SLC10A6, SLCO1A2, SLCO2B1, SLCO3A1, SLCO4A1) and 4 genes encoding estrogen biosynthetic/metabolic enzymes (HSD17B1, HSD17B2, STS and SULT1E1) and estrogen receptors (ESR1 and ESR2) were measured using RT-qPCR.

Result(s)* The results revealed that CE affects the expression of genes encoding E1-S transporters and estrogen biosynthetic and metabolic enzymes only at very high concentrations of CE $(50 \mu \mathrm{g} / \mathrm{ml}$ or $100 \mu \mathrm{g} / \mathrm{ml})$, while no changes in expression were observed with concentrations that are similar to those detected in plasma of CE users.

Conclusion* Our research presents an insight of CE effects on endometrial or ovarian cancer CLs at the mRNA level showing additional proof of safe usage of CE in healthy women and women with hormone-dependent malignancies like endometrial and ovarian cancer.

\section{MOLECULAR FEATURES AND PROGNOSTIC IMPACT OF MELF TYPE MYOMETRIAL INVASION IN THE PORTEC-1/2 COHORT OF EARLY STAGE ENDOMETRIAL CANCERS}

${ }^{1}$ AS Van den Heerik*, ${ }^{2} \mathrm{~K}$ Aiyer, ${ }^{3}$ J Jurgenliemk-Schulz, ${ }^{4} \mathrm{~J} J o b s e n,{ }^{5} \mathrm{JW}$ Mens, ${ }^{6} \mathrm{~L}$ Lutgens, ${ }^{5} \mathrm{R}$ Nout, ${ }^{1} \mathrm{CL}$ Creutzberg, ${ }^{2} \mathrm{~V}$ Smit, ${ }^{1} \mathrm{~N}$ Horeweg, ${ }^{2} \mathrm{~T}$ Bosse. ${ }^{1}$ Leiden University Medical Center (LUMC), Radiation Oncology, Leiden, Netherlands; 'Leiden University Medical Center (LUMC), Pathology, Leiden, Netherlands; ${ }^{3}$ UMC Utrecht, Radiation Oncology, Utrecht, Netherlands; ${ }^{4}$ MST, Radiation Oncology, Enschede, Netherlands; ${ }^{5}$ Erasmus MC, Radiation Oncology, Rotterdam, Netherlands; ${ }^{6}$ Academic Hospital Maastricht, Radiation Oncology, Maastricht, Netherlands

\subsection{6/ijgc-2021-ESGO.169}

Introduction/Background* Microcystic, elongated fragmented (MELF) pattern of myometrial invasion is a distinct histologic feature occasionally seen in low-grade endometrial carcinomas (EC). The prognostic relevance of the presence of MELF is uncertain due to conflicting data and has not appropriately been studied in the context of the novel molecular EC classification. We aimed to determine the relation of MELF pattern of invasion with clinicopathological and molecular characteristics, and define its prognostic relevance in early stage (high) intermediate risk EC.

Methodology Single haematoxylin and eosin (H\&E) stained whole tumour slides of 929 of the 1141 early stage (high) intermediate risk EC of patients included in the post-operative radiation therapy in endometrial carcinoma (PORTEC)-1/-2 trials were available for review for the presence of MELF. Histological type, stage and grade, presence and extent of lymphvascular-space-invasion (LVSI), molecular subclass, L1-cell-adhesion-molecule (L1CAM) overexpression, and $\beta$-catenin exon-3 (CTNNB1) and KRAS mutational status were compared between MELF-positive and negative cases. Differences in patient and tumour characteristics were analysed with chisquare or Fisher's exact test for categorical and Mann-Whitney $U$ test for continuous variables. Time-to-event analyses were done using the Kaplan-Meier method, log-rank tests and Cox' proportional hazards models.

Abstract 577 Table 1 Clinicopathological features of MELF positive and negative cases

\begin{tabular}{|c|c|c|c|c|c|c|}
\hline & $\begin{array}{c}\text { Total } \\
\text { (n=929) }\end{array}$ & & $\begin{array}{l}\text { No MELF } \\
(n=800)\end{array}$ & & $\begin{array}{c}\text { MELF } \\
(n=129)\end{array}$ & P-value \\
\hline $\begin{array}{l}\text { Age } \\
\text { mean (range) }\end{array}$ & $68(67-68)$ & 68 & $(67-68)$ & 68 & $(67-69)$ & 0.88 \\
\hline $\begin{array}{l}\text { Histotype } \\
\text { endometrioid } \\
\text { non-endometrioid\# }\end{array}$ & $\begin{array}{ll}907 & (97.7 \%) \\
21 & (2.3 \%)\end{array}$ & $\begin{array}{l}781 \\
19\end{array}$ & $\begin{array}{l}(97.6 \%) \\
(2.4 \%)\end{array}$ & & $\begin{array}{l}(98.4 \%) \\
(1.6 \%)\end{array}$ & 0.54 \\
\hline $\begin{array}{l}\text { Stage } \\
\text { IA } \\
\geq 1 \mathrm{~B}^{*}\end{array}$ & $\begin{array}{ll}287 & (30.9 \%) \\
641 & (69,1 \%)\end{array}$ & $\begin{array}{l}280 \\
520\end{array}$ & $\begin{array}{l}(35.0 \%) \\
(65.0 \%)\end{array}$ & & $\begin{array}{l}(5.4 \%) \\
(94.6 \%)\end{array}$ & $<0.0001$ \\
\hline $\begin{array}{l}\text { Grade } \\
1-2 \\
3 \\
\end{array}$ & $\begin{array}{ll}792 & (85.3 \%) \\
136 & (14.7 \%)\end{array}$ & $\begin{array}{l}668 \\
132 \\
\end{array}$ & $\begin{array}{l}(83.5 \%) \\
(16.5 \%)\end{array}$ & $\begin{array}{l}125 \\
4\end{array}$ & $\begin{array}{l}(96.9 \%) \\
(3.1 \%)\end{array}$ & $<0.0001$ \\
\hline $\begin{array}{l}\text { IVSI } \\
\text { none or mild } \\
\text { substantial }\end{array}$ & $\begin{array}{ll}823 & (95.3 \%) \\
40 & (4.6 \%)\end{array}$ & $\begin{array}{l}712 \\
30\end{array}$ & $\begin{array}{l}(96.0 \%) \\
(4.0 \%)\end{array}$ & & $\begin{array}{l}(91.8 \%) \\
(8.2 \%)\end{array}$ & 0.06 \\
\hline $\begin{array}{l}\text { LICAM } \\
\leq 10 \% \text { (negative) } \\
>10 \% \text { (positive) }\end{array}$ & $\begin{array}{ll}750 & (94.6 \%) \\
43 & (5.4 \%) \\
\end{array}$ & $\begin{array}{l}638 \\
41 \\
\end{array}$ & $\begin{array}{l}(94.0 \%) \\
(6.0 \%)\end{array}$ & $\begin{array}{l}113 \\
2\end{array}$ & $\begin{array}{l}(98.3 \%) \\
(1.7 \%)\end{array}$ & 0.03 \\
\hline $\begin{array}{l}\text { TCGA molecular } \\
\text { subgroups } \\
\text { POLE mutant } \\
\text { MMRd } \\
\text { p53 abnormal } \\
\text { NSMP }\end{array}$ & $\begin{array}{ll}57 & (7.1 \%) \\
226 & (28.2 \%) \\
38 & (4.7 \%) \\
480 & (60.0 \%)\end{array}$ & \begin{tabular}{|l}
55 \\
212 \\
37 \\
386
\end{tabular} & $\begin{array}{l}(8.0 \%) \\
(30.8 \%) \\
(5.4 \%) \\
(55.9 \%)\end{array}$ & \begin{tabular}{|l}
2 \\
14 \\
1 \\
95
\end{tabular} & $\begin{array}{l}(1.8 \%) \\
(12.5 \%) \\
(0.9 \%) \\
(84.8 \%)\end{array}$ & \\
\hline $\begin{array}{l}\text { CTNNB-1 } \\
\text { wild type } \\
\text { mutation }\end{array}$ & $\begin{array}{ll}684 & (79.7 \%) \\
174 & (20.3 \%)\end{array}$ & $\begin{array}{l}575 \\
164 \\
\end{array}$ & $\begin{array}{l}(77.8 \%) \\
(22.2 \%)\end{array}$ & \begin{tabular}{|l|}
110 \\
10
\end{tabular} & $\begin{array}{l}(91.7 \%) \\
(8.3 \%)\end{array}$ & $<0.0001$ \\
\hline $\begin{array}{l}\text { KRAS } \\
\text { wild type } \\
\text { mutation }\end{array}$ & $\begin{array}{ll}714 & (83.2 \%) \\
144 & (16.8 \%)\end{array}$ & $\begin{array}{l}623 \\
116\end{array}$ & $\begin{array}{l}(84.3 \%) \\
(15.7)\end{array}$ & $\begin{array}{l}92 \\
28\end{array}$ & $\begin{array}{l}(76.7 \%) \\
(23.3 \%)\end{array}$ & 0.05 \\
\hline
\end{tabular}

